
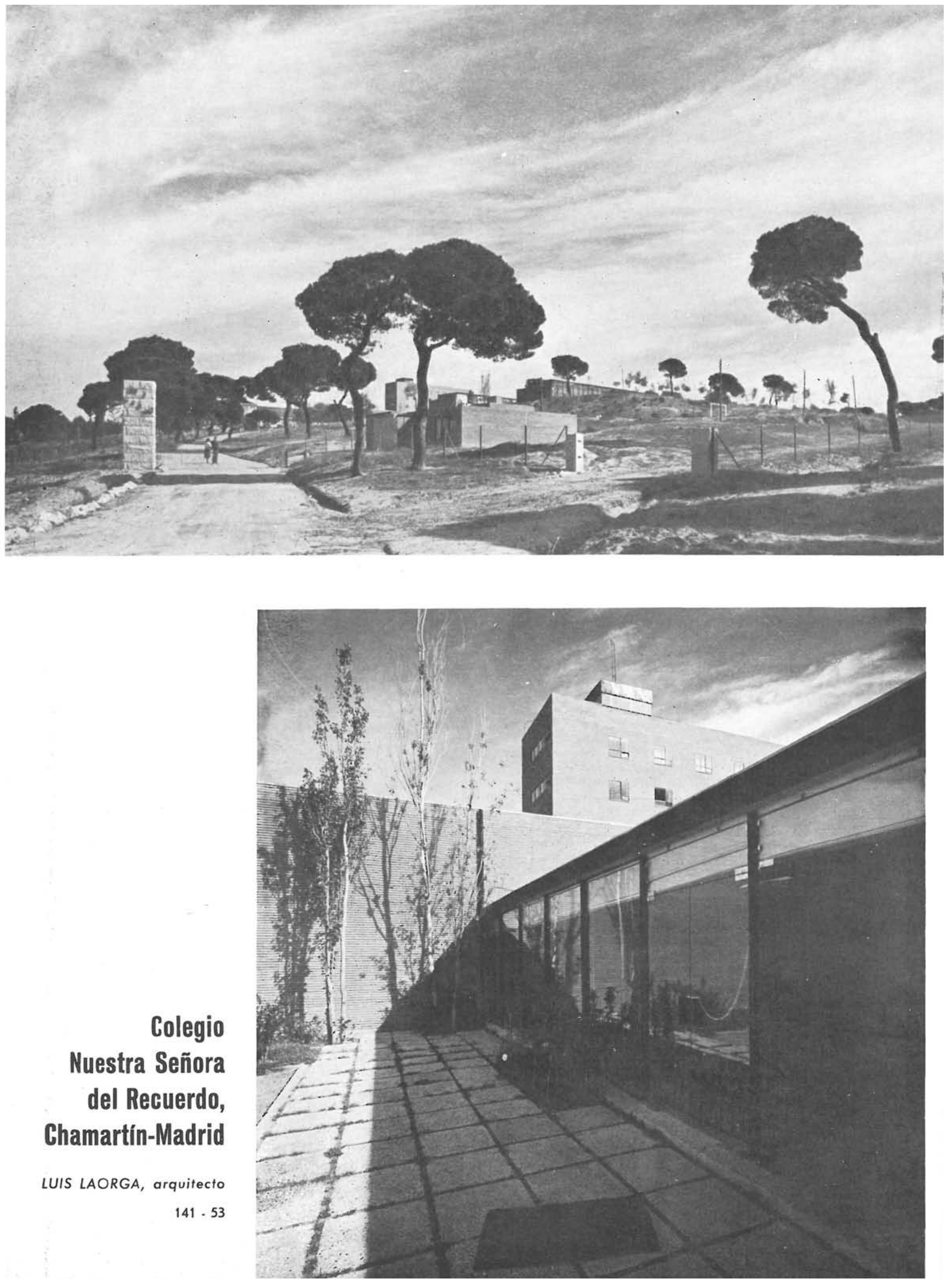
El planeamiento y desarrollo de un proyecto de colegio está condicionado por el sistema pedagógicó que en él se ha de poner en práctica.

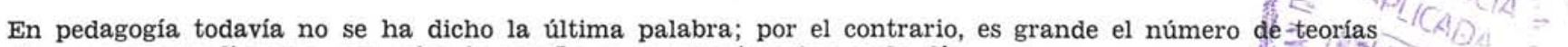
diversas-y aun dispares-que sobre la enseñanza se experimentan cada día.

Esta es una de las razones por las que se advierten en las construcciones escolares tal diversidad de modalidades aún en las realizadas en las mismas localidades y tiempo.
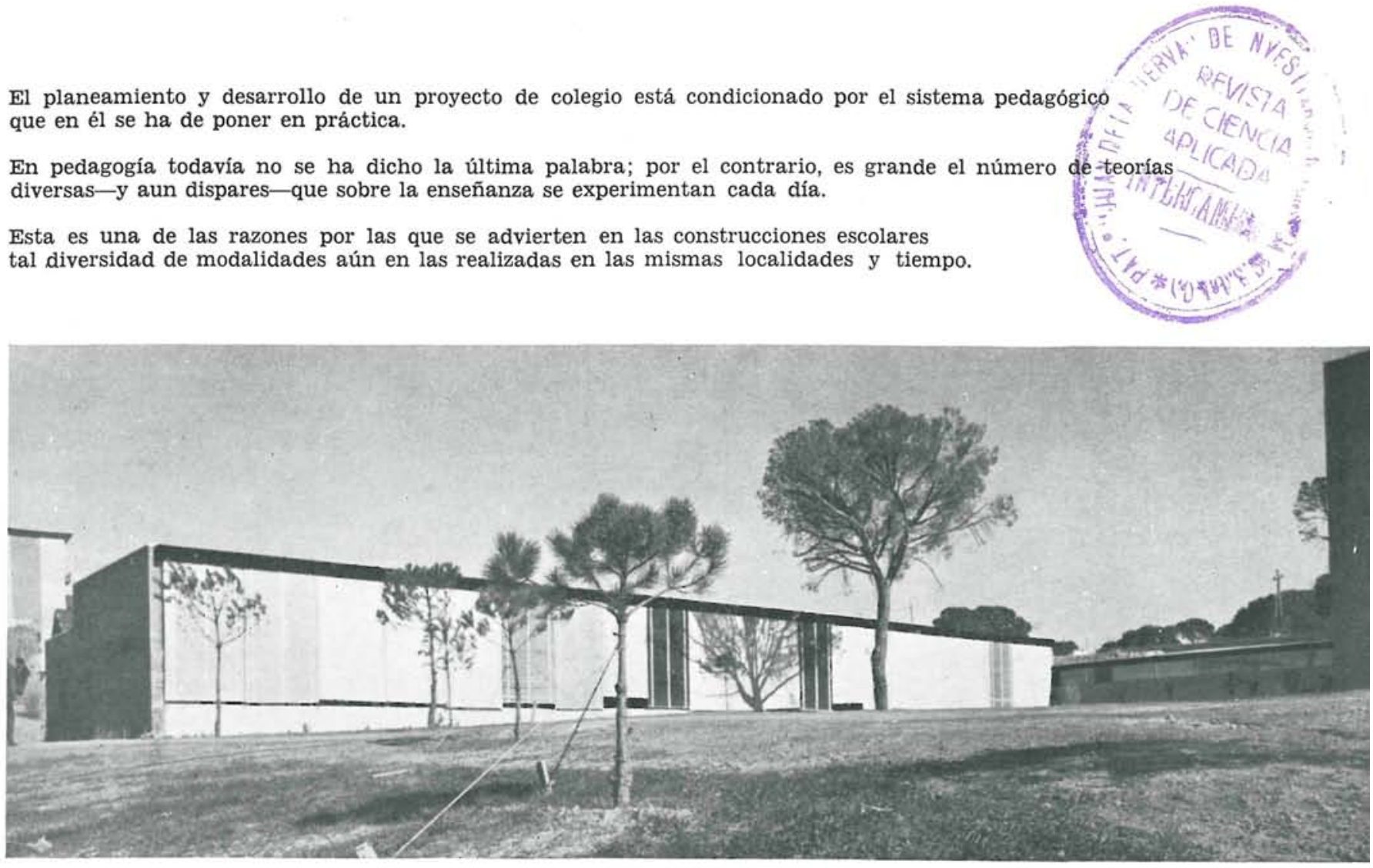

La Compañía de Jesús, propietaria de este colegio,

tiene la experiencia de varios siglos dedicada a la enseñanza de niños y jóvenes y, como consecuencia, posee ideas muy concretas en cuanto a métodos, sistemas, etc.

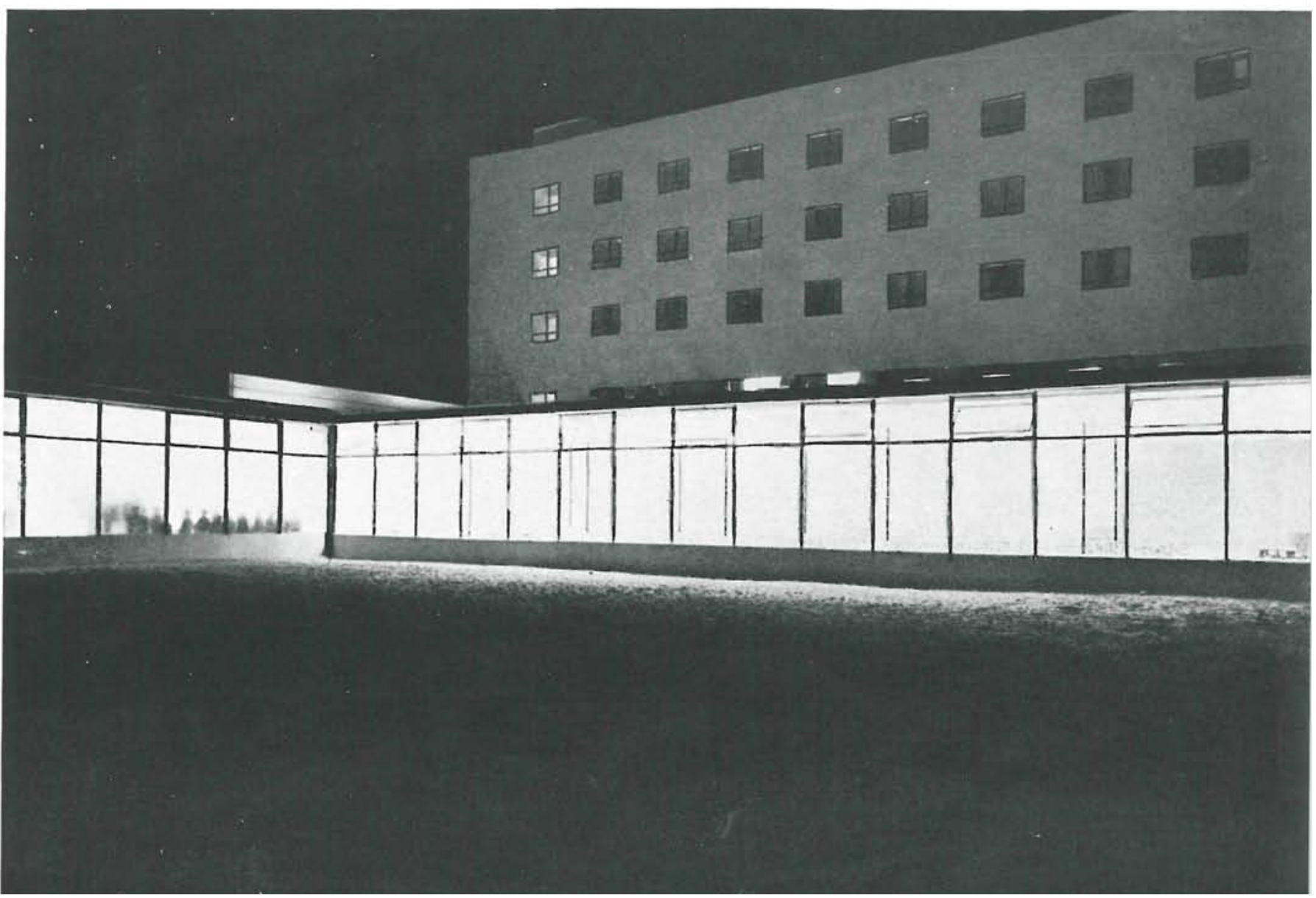



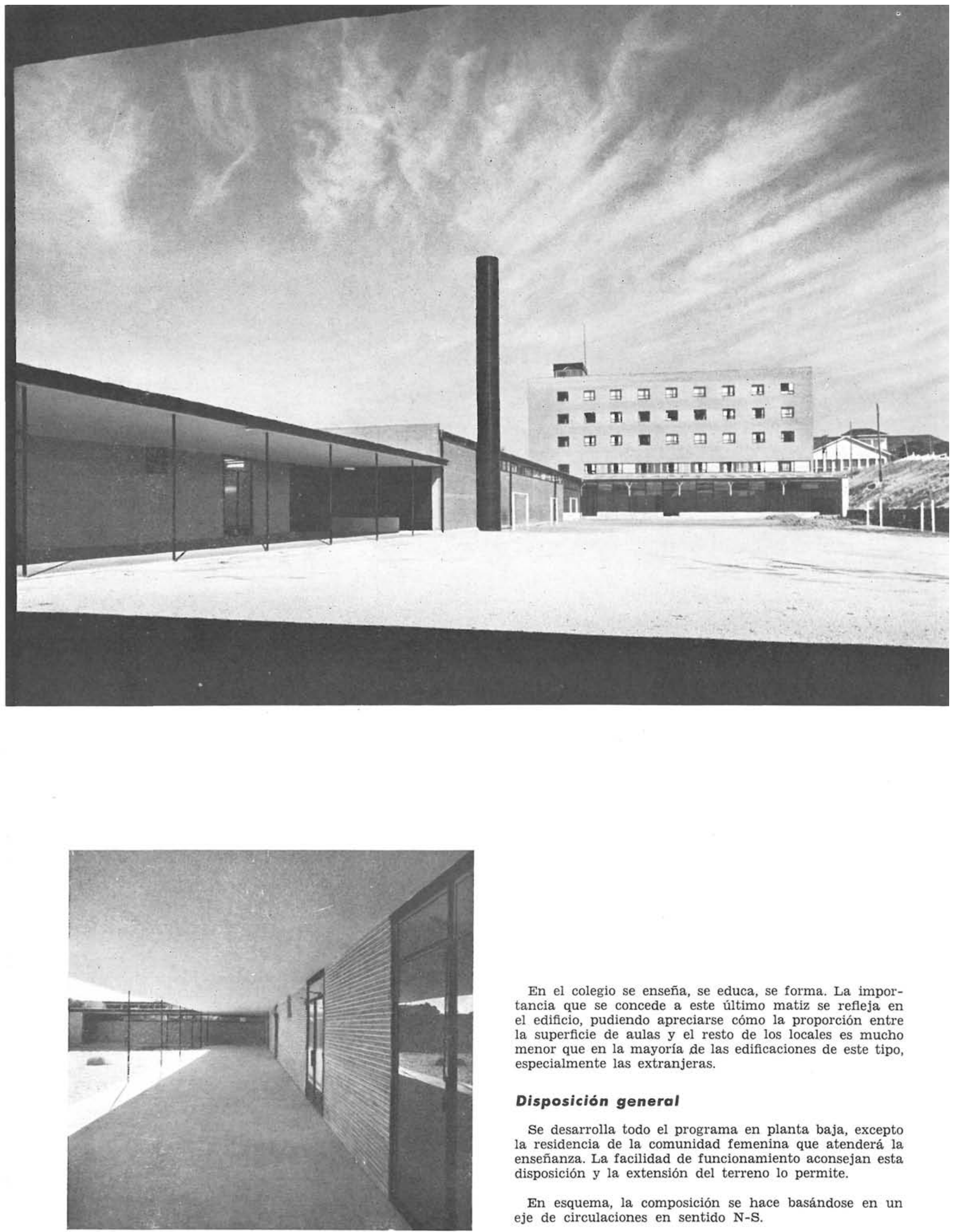

En el colegio se enseña, se educa, se forma. La importancia que se concede a este último matiz se refleja en el edificio, pudiendo apreciarse cómo la proporción entre la superficie de aulas y el resto de los locales es mucho menor que en la mayoría de las edificaciones de este tipo, especialmente las extranjeras.

\section{Disposición general}

Se desarrolla todo el programa en planta baja, excepto la residencia de la comunidad femenina que atenderá la enseñanza. La facilidad de funcionamiento aconsejan esta disposición y la extensión del terreno lo permite.

En esquema, la composición se hace basándose en un eje de circulaciones en sentido $\mathrm{N}-\mathrm{S}$. 

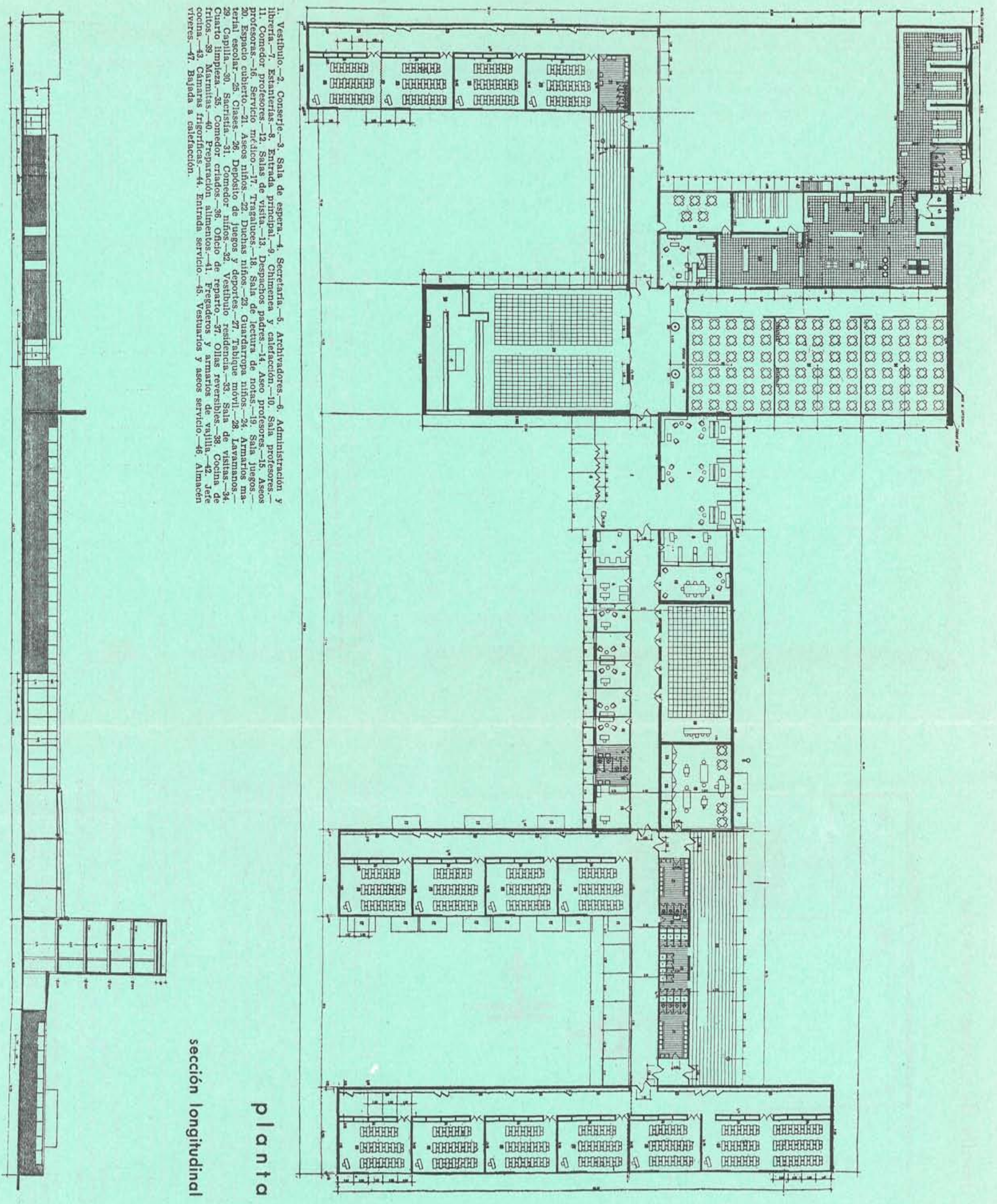


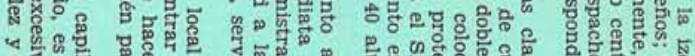

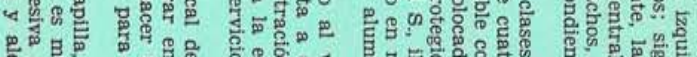

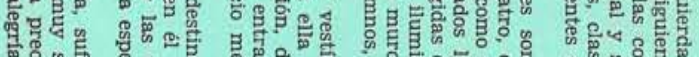

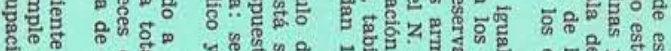

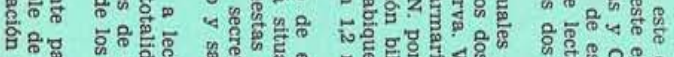

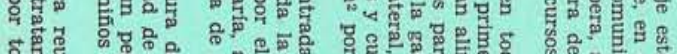

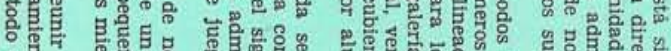

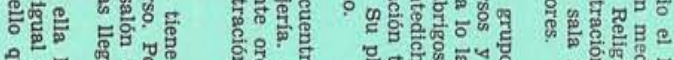

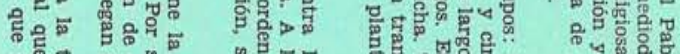

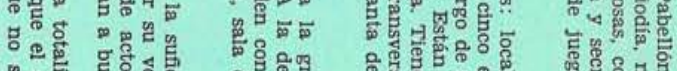

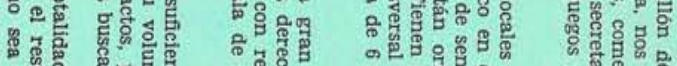

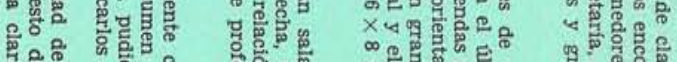

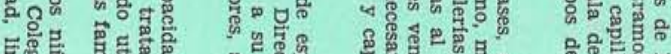

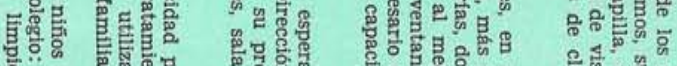

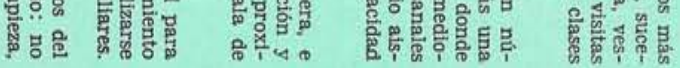

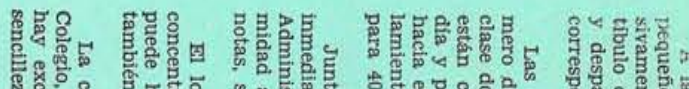

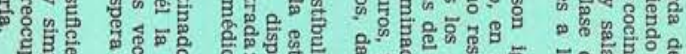

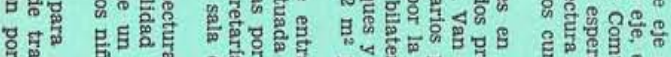
品

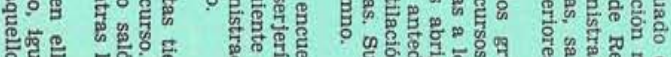

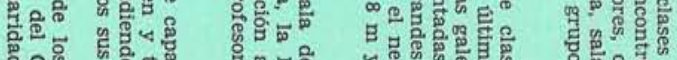

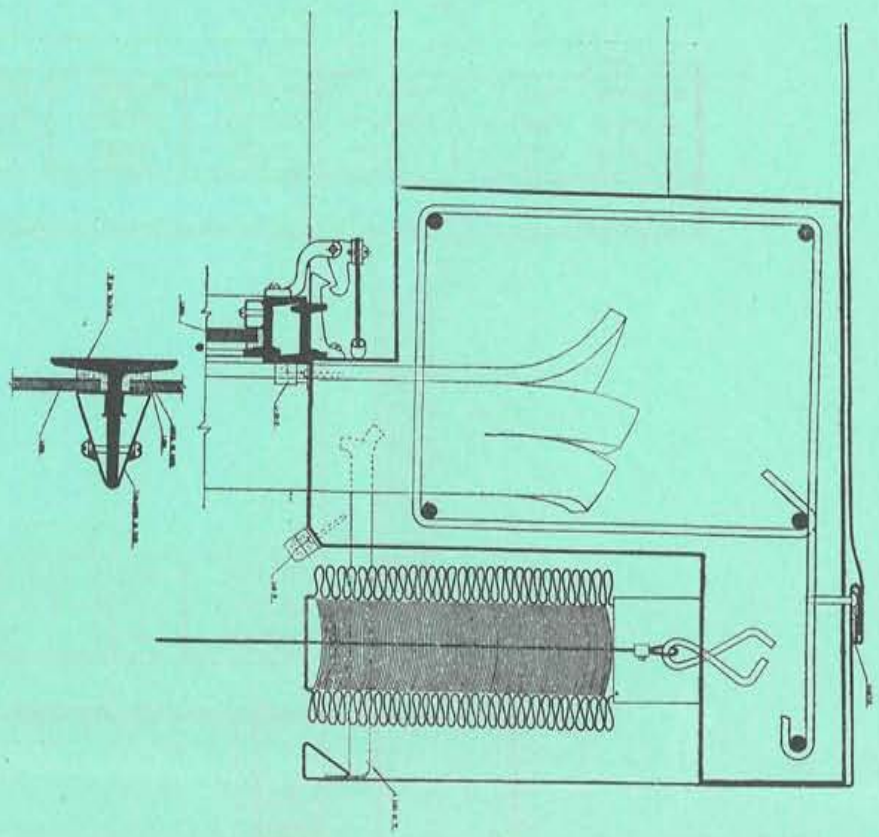

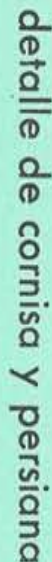
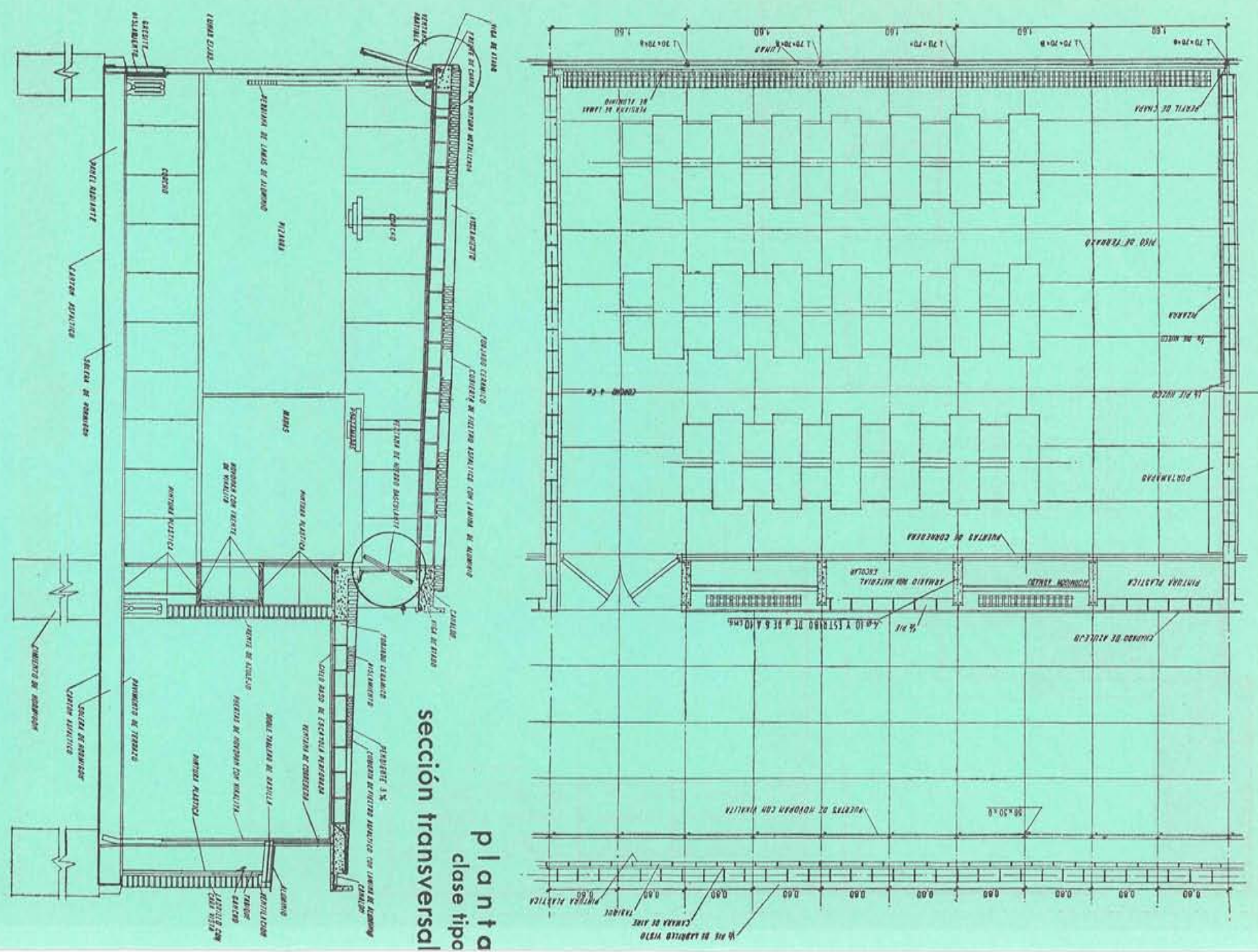
El volumen es paralelepipédico, con un muro lateral de ladrillo visto; el fondo del altar está chapado en mármol; el testero posterior es de madera en la parte de puertas, y celosías de hierro cierran el coro. El muro longitudinal orientado al $\mathrm{N}$. fué proyectado con una gran vidriera artística, y la cubierta, con una estructura tubular, completa el volumen en que las distintas calidades de los elementos enumerados contribuyen a conseguir el efecto estético buscado.

Los comedores están dispuestos en locales independientes, relacionados con el oficio de reparto: por un lado, los tres destinados a niños; por otro, los de profesores y criados, y sobre el oficio, como comunicación vertical, el de la Comunidad.

La Comunidad de Religiosas se dispone en cuatro plantas sobre la cocina. Tiene entrada independiente dentro del propio Colegio, a través de un pequeño vestíbulo, de donde arranca la escalera y ascensor que comunica con las plantas sucesivas. En una primera entreplanta está la entrada al coro, situado en la parte posterior de la entrada del Colegio. En la planta primera se sitúan: los dos despachos y sala de visitas; el refectorio, con montaplatos que lo une a la cocina; sala de comunidad; oratorio privado $\mathrm{y}$ un pequeño aseo. En las tres plantas sucesivas se hallan los dormitorios individuales, orientados al mediodía, con lavabo individual y armario empotrado. En uno de los extremos de la galería, a la que dan todos los dormitorios, se sitúan los aseos generales, retretes y duchas. En la última planta, y con entrada independiente de la escalera, se reserva un dormitorio de muchachas internas al servicio del Colegio.

Se disponen dos zonas de sótanos para instalar, respectivamente, las calderas de calefacción y productores de agua caliente, correspondientes al Colegio y a la Residencia, las cuales han de ser independientes y que por mayor economía de funeionamiento, deben colocarse centradas respecto al área de esificación a que deben servir.
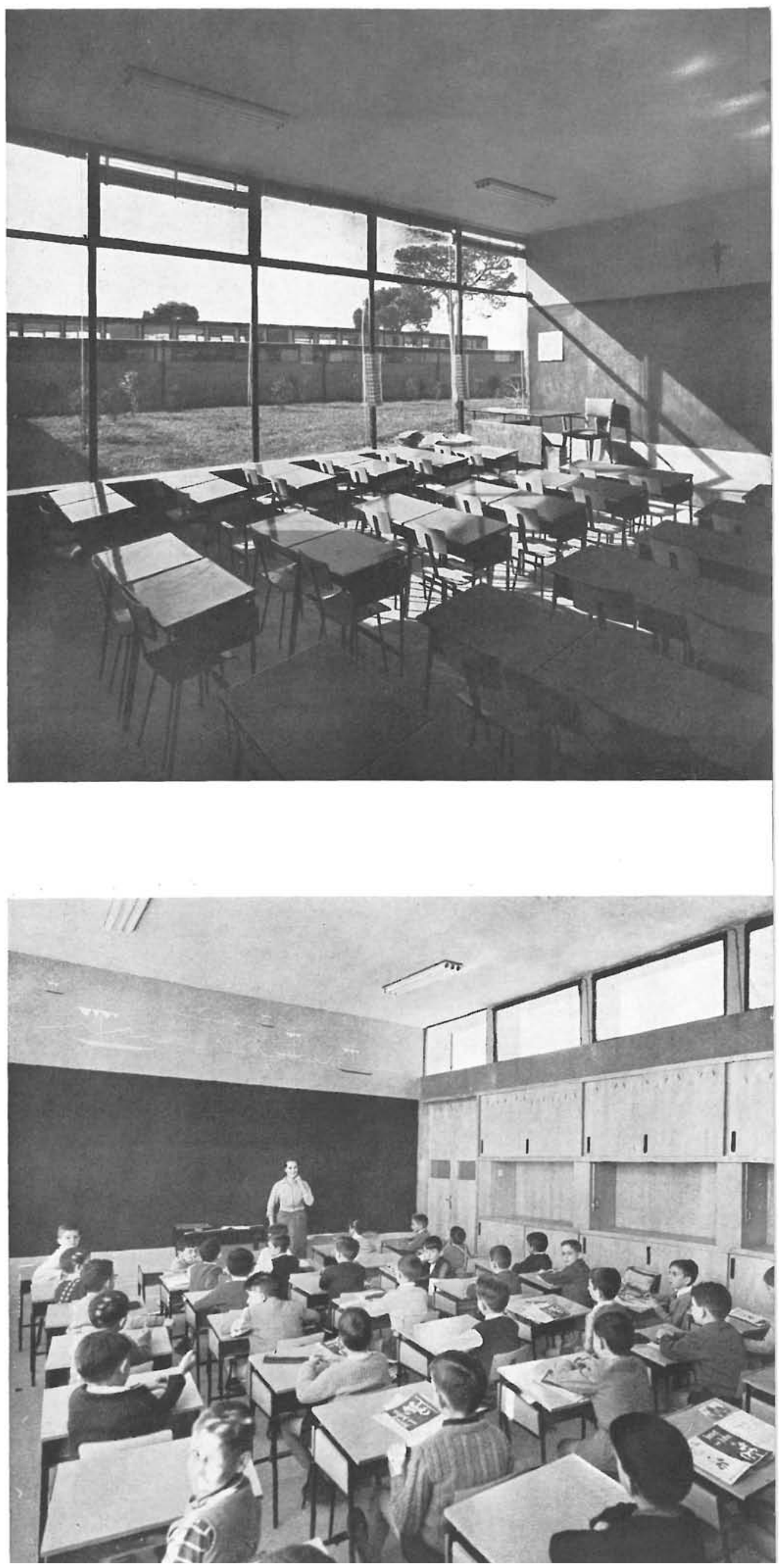

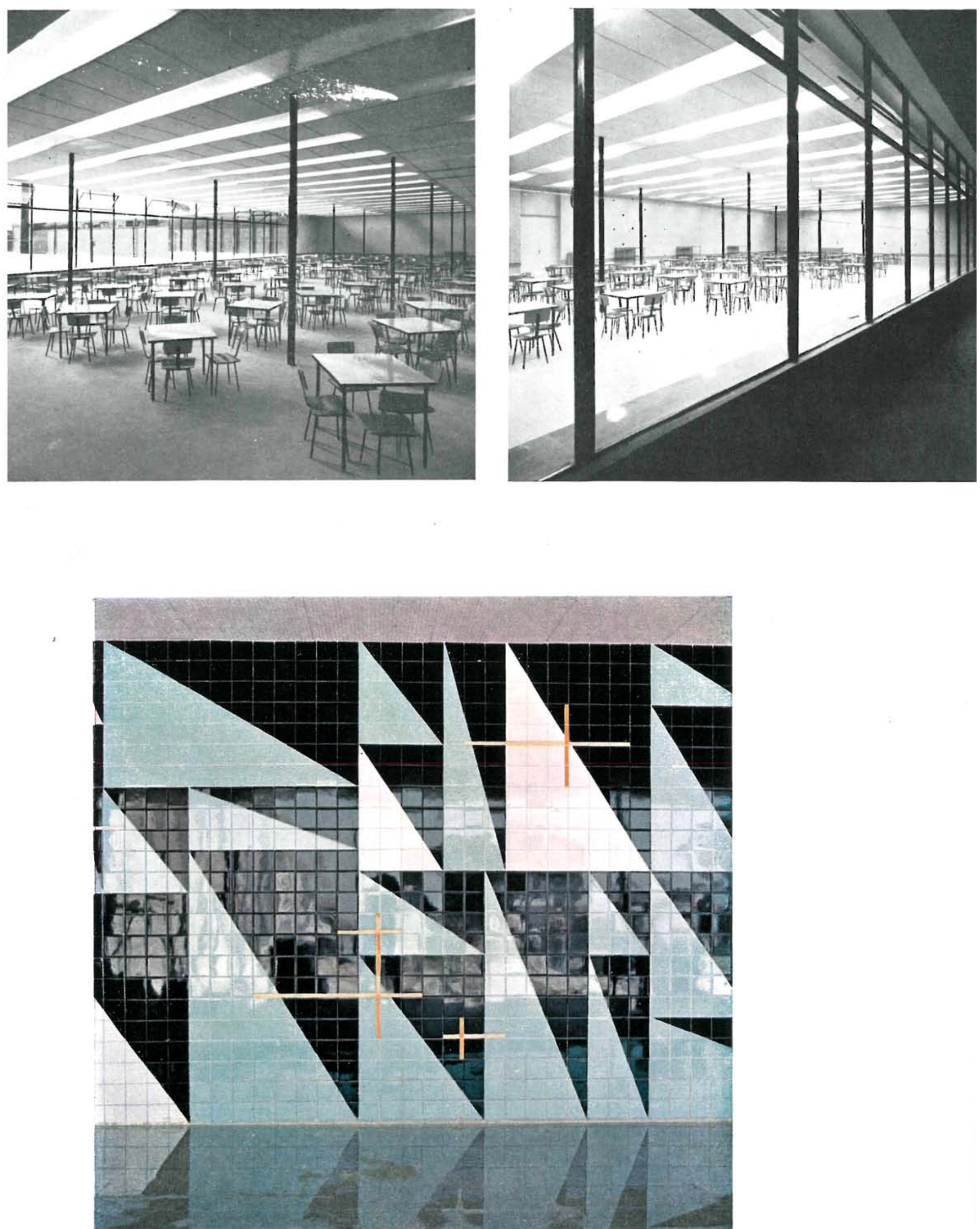

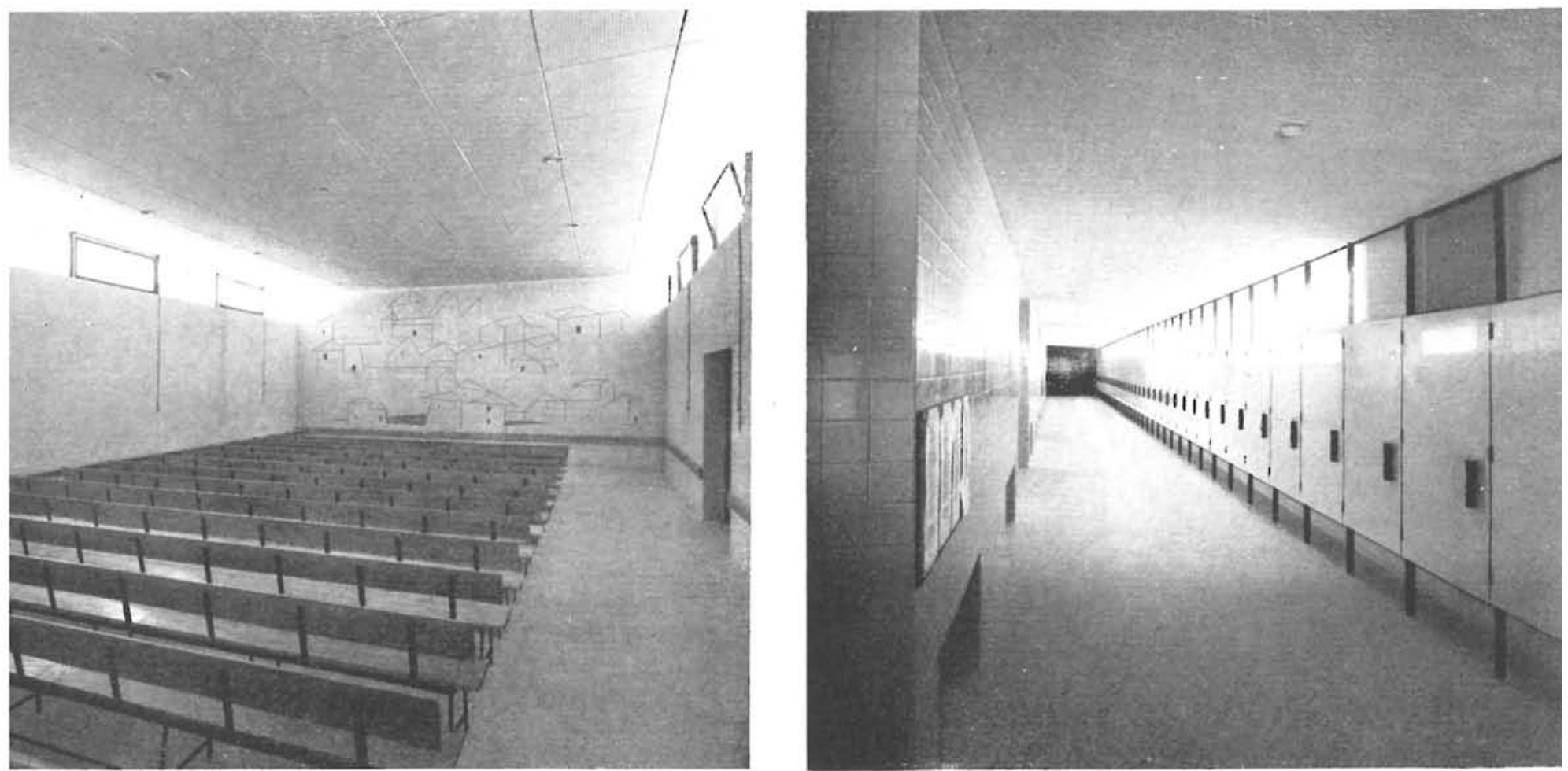

\section{Construcción}

El proyecto de este Colegio se ha orientado en el sentido de una construcción ligera de carácter definitivo. Los materiales fueron utilizados para sacar el mayor partido decorativo; su ligereza deriva del tratamiento de alturas y del empleo de los materiales.

La construcción en una planta, para la mayor parte del edificio, permite realizar una cimentación muy somera, repercutiendo en un ahorro en la obra enterrada en beneficio de la obra vista: muros de poco espesor y soportes de secciones reducidas, y a forjar techos muy livianos y económicos. La cubierta se apoya sobre muros de cerramiento, cuyos espesores oscilan entre medio pie y pie y medio, y en perfiles de acero laminado de escuadrías normales en las cristaleras. La mayor parte de la construcción se cubre por forjados autárquicos hasta luces de 6 metros, con vigas de atados sobre muros y soportes. Cuando las luces exceden de $6 \mathrm{~m}$, se emplean: vigas de hormigón, en el comedor; cerchas metálicas ligeras, en el cuerpo central; y estructura tubular, en la capilla.

Como revestimiento y aislamiento para la absorción de sonidos en tabiques entre clases se aplica el corcho.

Situando bajo soleras, en toda la extensión del edificio, láminas de fieltro asfáltico soldado, impiden la penetración de humedades en planta baja.
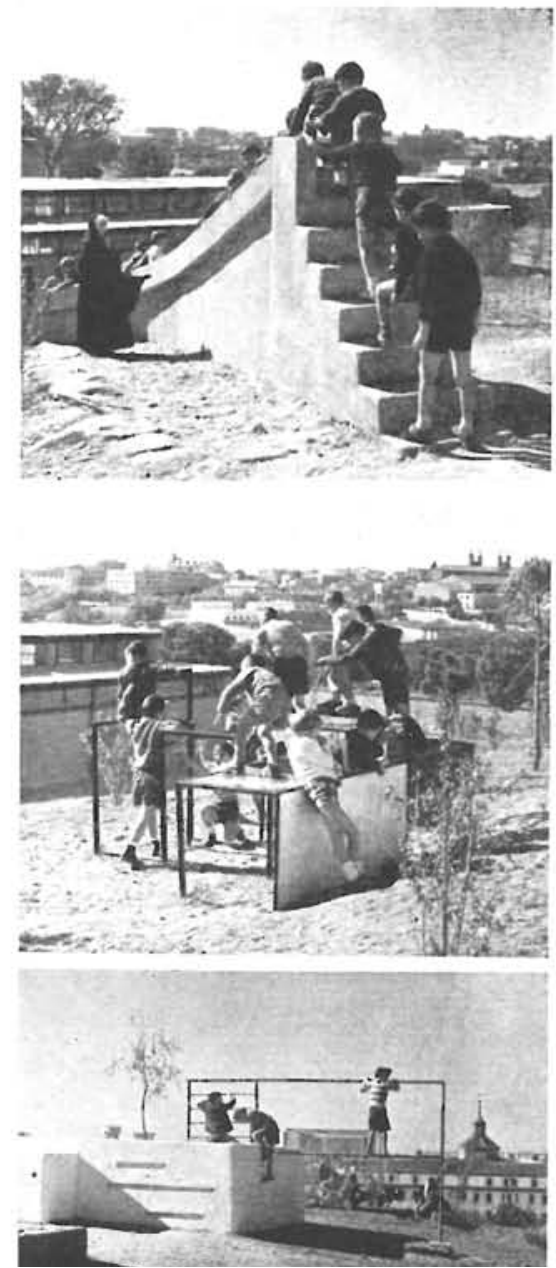


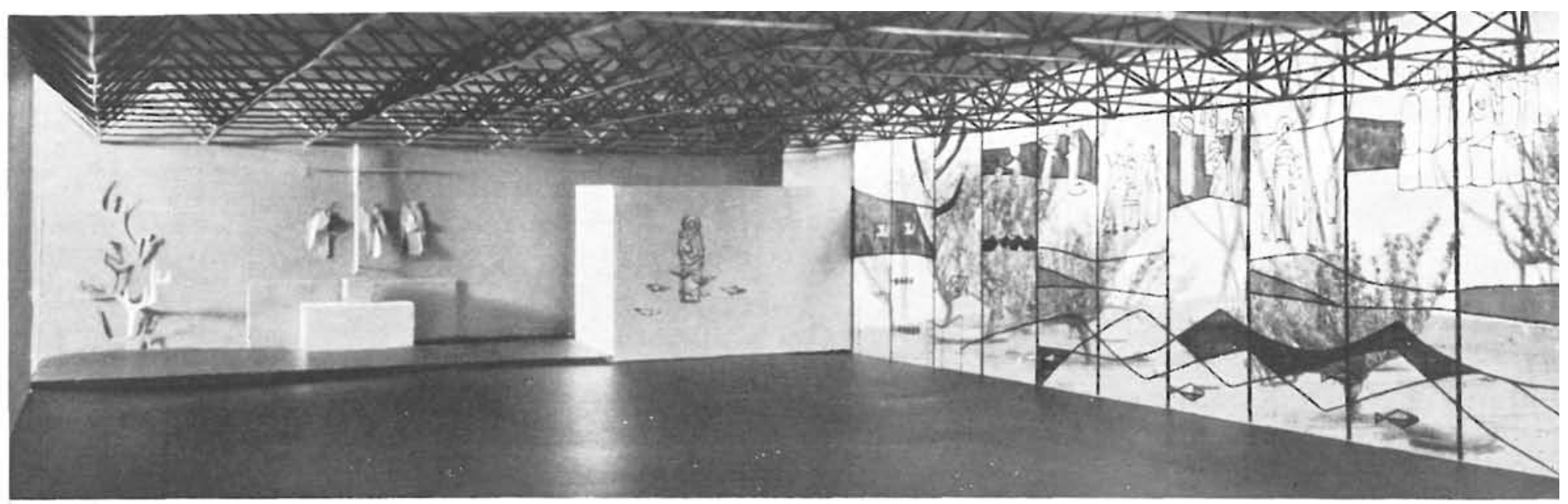

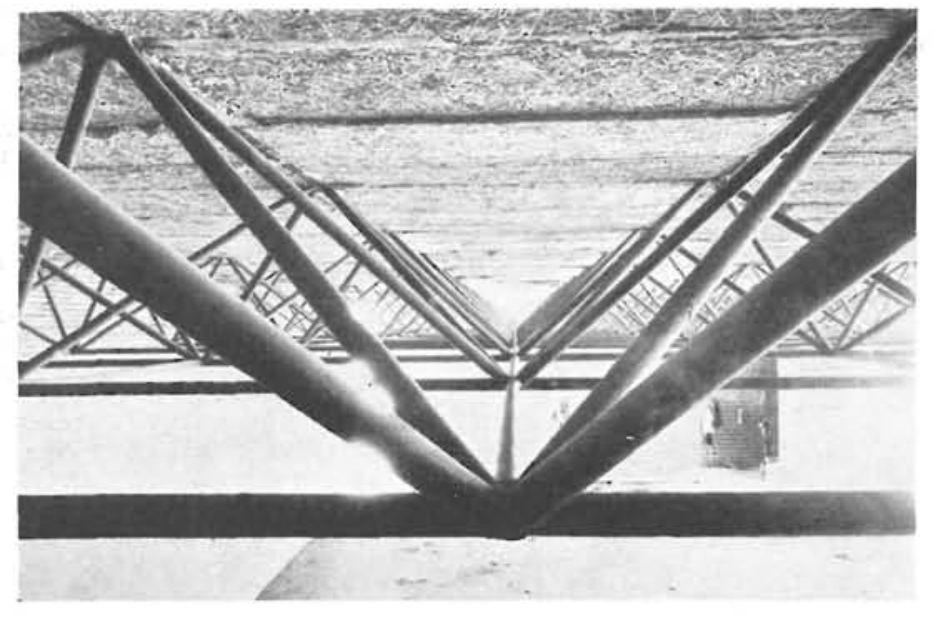
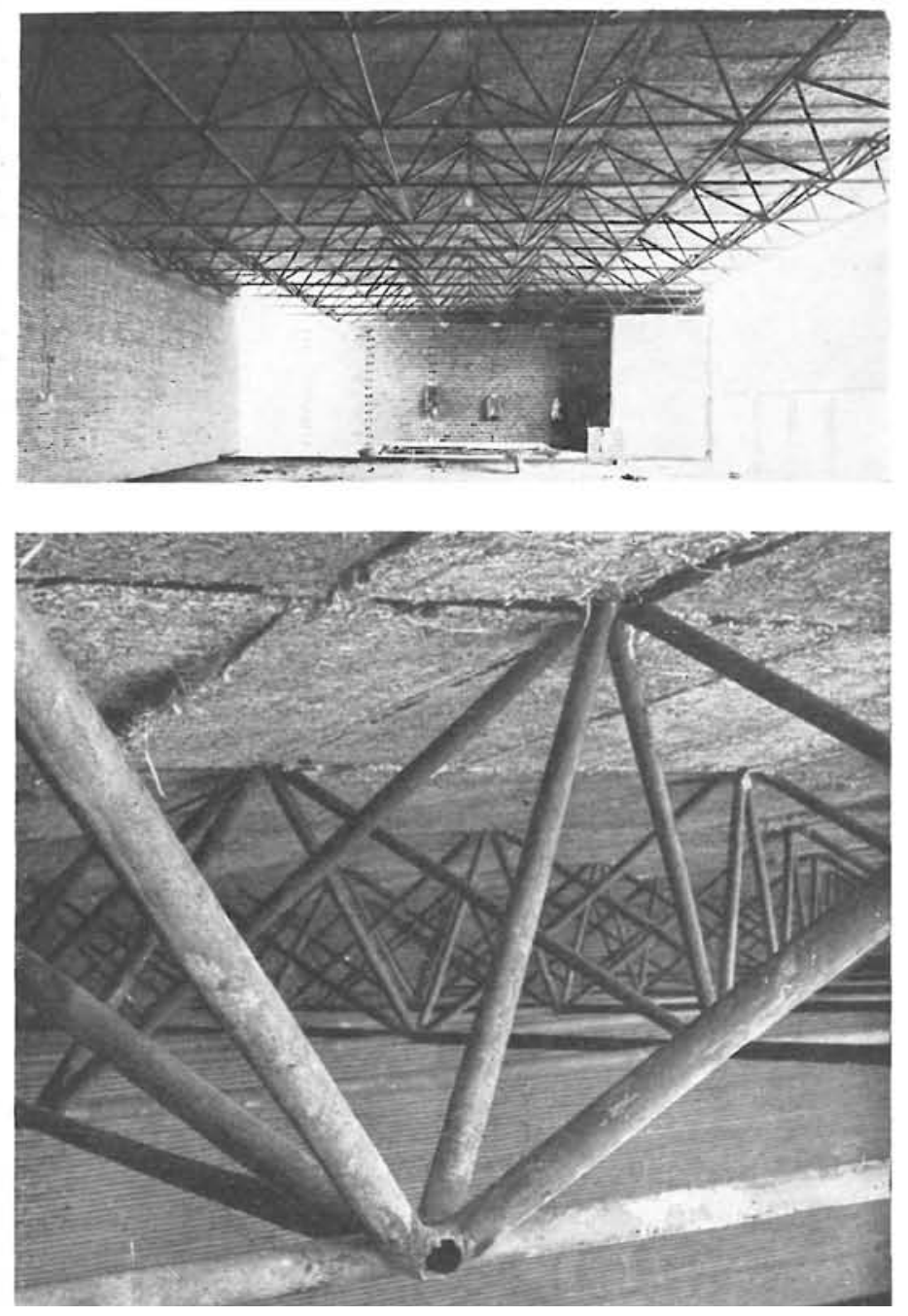

La carpintería es muy liviana. Los criterios nuevos de empleo de chapa plegada reduce a revestimiento de estructura lo que pudiera ser una partida de muchísimo volumen. Las lunas van montadas sobre perfiles especiales, estiradas en hilera y ejecutadas en chapa.

Los pavimentos son de tipo continuo en todo el Colegio, en tonos claros, con juntas de dilatación en latón. Las paredes de pasillos van chapadas, para su conservación permanente, en azulejo, desarrollándose, junto al vestíbulo, una interesante composición plástica a base de azulejos azul, celeste, blanco y naranja.

\section{Instalaciones}

La instalación de calefacción, a pesar de lo liviano y abierto de la edificación, está muy ayudada en su rendimiento por la orientación mediodía, que produce efecto de invernadero en la mayor parte de los días de la estación fría. Se proyecta con radiadores colocados junto a los ventanales de fachada y convectores en las clases y comedor.

Fotos: M. G O MOYA Y FÉRRIZ 


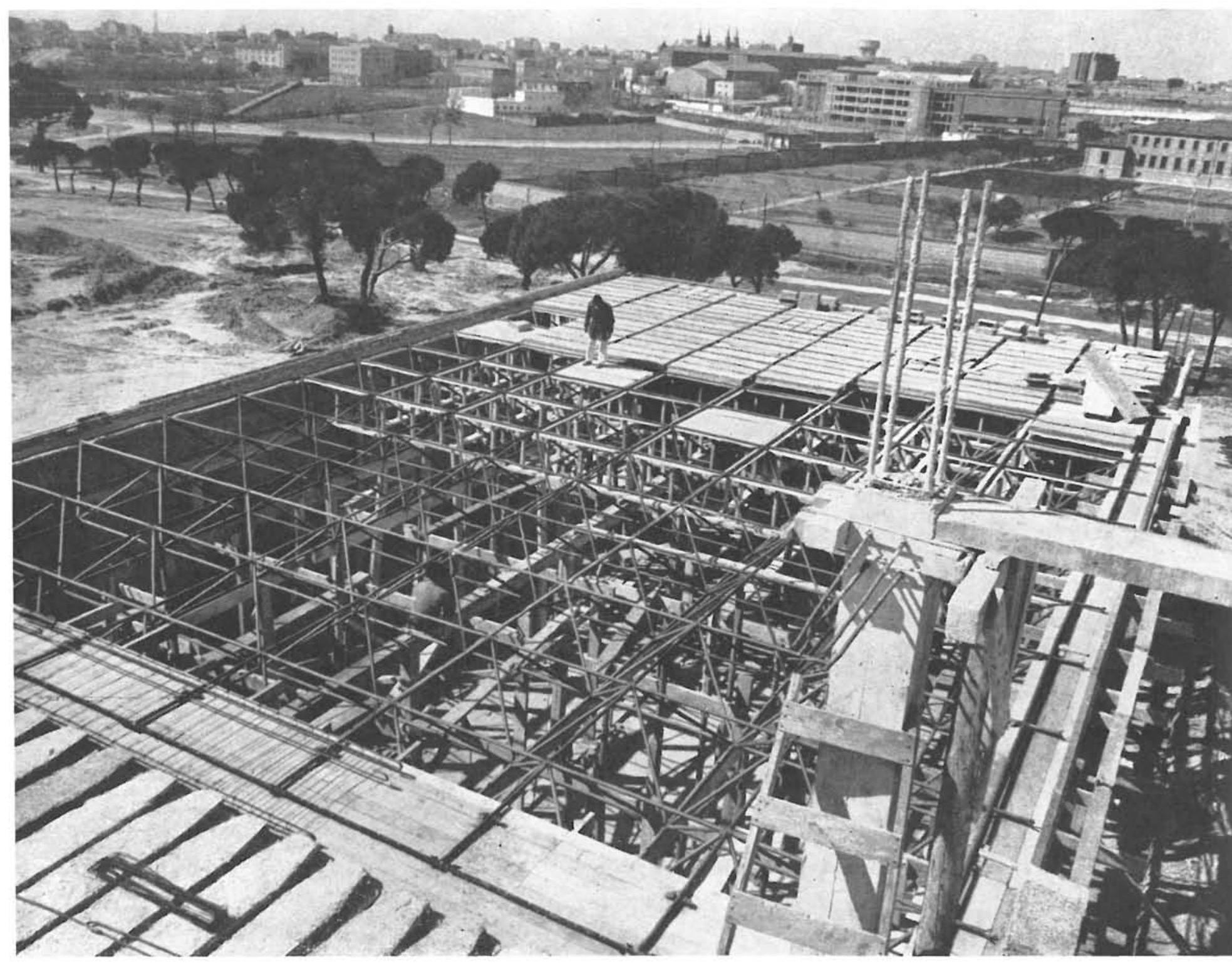

La instalación eléctrica, como corresponde al carácter del edificio, está dimensionada y proyectada para alcanzar las alturas de iluminación que garantice la salud de la vista de los niños. En las clases, los niveles de iluminación no son nunca inferiores a los 150 luxes. En despachos, oficinas y capilla se alcanzan los 125 , en pasillos y vestíbulos se adoptan 30 y en el comedor y cocina 75 luxes. La distribución se efectúa a partir de un cuadro general, situado en conserjería, con circuitos independientes a cada uno de los distintos sectores del Colegio; dentro de cada uno de los sectores, se subdividen los circuitos hasta poder dejar aisladas cada una de las clases. 